This is an Accepted Manuscript of an article published by Taylor \& Francis in Criminal Justice Ethics, 2015. Published online on 31 Mar 2015, at: http://www.tandfonline.com/10.1080/0731129X.2015.1025505.

\title{
Time and Crime: Which Cold-Case Investigations Should Be Reheated?
}

Jonathan A Hughes and Monique Jonas

\begin{abstract}
:
Advances in forensic techniques have expanded the temporal horizon of criminal investigations, facilitating investigation of historic crimes that would previously have been considered unsolvable. Public enthusiasm for pursuing historic crimes is exemplified by recent high-profile trials of celebrities accused of historic sexual offences. These circumstances give new urgency to the question of how we should decide which historic offences to investigate. A satisfactory answer must take into account the ways in which the passage of time can erode the benefits of criminal investigation, the costs associated with investigating old crimes, and the need to prioritize investigations in the face of limited police resources. This article emphasizes the first of these factors. It begins by considering the moral goals of a criminal justice system and the contribution of criminal investigations to the achievement of these goals, distinguishing between contributions that depend on further steps in the criminal justice process, such as prosecution and punishment, and contributions that can have value independently of these further steps. Using this important distinction, the article then examines a range of factors that relate the passage of time to criminal justice goals, including the seriousness of the crime; deterioration of evidence; death of the offender, victim and others affected by the crime; and diminished psychological connectedness between those affected by the crime and their current selves. While the range and non-uniformity of relevant factors preclude a simple answer to the question of when historic crimes should be investigated and call instead for case-by-case assessment, we find that the analysis does support some general conclusions that can guide such an assessment.
\end{abstract}

Key words: investigation, justice, punishment, cold cases, historic crimes, time 


\section{Introduction}

Developments in forensic science have altered the horizon of criminal investigation in a number of ways. Advances in DNA profiling have been notable in this respect, providing a valuable source of evidence that was unavailable to investigators in the past. If sufficient physical evidence exists, forensic scientific techniques such as DNA profiling can be used to positively identify the perpetrators of crimes committed many years ago.

These advances have increased the viability of cold-case investigations - investigations of crimes that have not been actively pursued for several years. Police forces in various jurisdictions have embraced the possibility of resolving such cases by establishing dedicated cold-case teams. Their efforts have yielded a number of high-profile successes and have perhaps increased enthusiasm for pursuing historic crimes even in the absence of DNA evidence. In some cases, offenders have been identified and punished many years after the original investigation of a crime failed to identify them or to produce sufficient evidence to support a prosecution. In other cases, crimes have been reported or discovered and investigated for the first time long after they occurred. Recent high-profile trials of celebrities accused of historic sexual offending in the United Kingdom vividly exemplify this trend. In some cases, re-investigation has also exonerated persons long suspected of, or even punished for, serious crimes. ${ }^{1}$ Some jurisdictions have responded to public concern with historic crimes and the increased opportunities offered by DNA technology by relaxing or abolishing statutes of limitations for certain types of offence. ${ }^{2}$

Cold case investigations raise interesting questions about the role of a criminal justice system (CJS). These questions are sometimes voiced by the media or the general public in response to a specific investigation, but they draw upon general reservations about the susceptibility of criminal wrongdoing to delayed correction. Do cold-case investigations serve justice or other legitimate CJS goals in the same manner or to the same extent as contemporaneous investigations? Does the prospect of achieving those goals survive the passage of time to a sufficient degree to support cold-case investigations? And what of the costs of criminal investigation: what effect does time have upon them?

Intuitively, time does appear to have an impact upon the appropriateness of criminal investigation. Consider the disappearance in Sussex in 1926 of 16-year-old servant Emma Alice 
Smith. Although Emma's disappearance was reported to the police by her family, the investigation was short-lived and failed to produce any conclusions. In early 2009, it was reported that the Sussex Major Crimes Unit was re-opening the case in response to newly emerged evidence of a death-bed confession of Emma's murder that had been made to her sister Lillian in 1953 (Guardian, February 4, 2009). Members of Emma's family stated that they had decided at the time not to report that confession to the police, because even then the murder had taken place so long ago. Although Sussex police were willing to re-investigate, Detective Chief Inspector Trevor Bowles told a local reporter: "It is an intriguing and very unusual case. However, we would like to make it clear this is not a priority and we will not be putting great resources into it" (Crawley News, February 6, 2009). In interviews given to newspapers, a police spokesperson made clear that the purpose of their investigation was not to positively identify the killer, if there was one, but rather to locate Emma's body, to allow for it to receive a proper burial.

Statements like those made by Sussex police and Emma Alice Smith's family express what may be widely shared thoughts about the degrading effect of time upon the value of criminal investigations. It seems appropriate to do something in response to a confession of a murder committed long ago, but what exactly should be done? The harm done to Emma is no less serious for having been committed long ago. What is more, it has stood uncorrected and unaddressed for over 80 years. How does this passing of time tell against addressing it now?

One aspect of this case that militates against a concerted investigation is the fact that the confession was made on the (self-professed) killer's deathbed. The death of the major suspect potentially has a fatal effect on some of the key moral goals of criminal justice, such as those relating to retribution, public safety and, to some extent, its communicative or expressive function. But not all the goals of a CJS die with the suspect, and criminal investigations into crimes the perpetrator of which is strongly suspected to be dead (suicide-bombings and murdersuicides, for instance) are routine. As time passes, the likelihood that the offender is still alive and able to be brought to justice decreases, but, as we shall see, other morally compelling reasons for investigating might remain. 
A cold-case investigation into a possible murder committed 86 years previously will appear to many of us to be right on the edge of moral viability. Even the most fervent advocate of the righting of past wrongs will acknowledge that an edge exists, even if views differ as to its location. Consider, for instance, the oldest known potential cold case, that of the 5000-year-old mummified corpse of a Neolithic hunter known as Ötzi, discovered in the Ötztal Alps in 1991. Examinations suggest that Ötzi was probably murdered. Imagine now that a perfectly preserved potential murder weapon and a large burial site are discovered nearby, containing remains dated to the same time-period as Ötzi's corpse. It may be possible to apply forensic techniques to all this intact physical evidence to identify the likely perpetrator. This would be interesting work for forensic anthropologists, but no-one would seriously argue that the police ought to undertake it. The investigation of murders committed 5000 years ago lies decidedly outside the remit of the modern police service.

The passage of time can affect the ability of criminal investigations to serve the moral goals of a CJS, and it can also affect the costs of investigation. Investigations involve costs of several varieties: financial costs sustained by the state and also by suspects; opportunity costs relating to other possible uses of police time and resources; and the personal costs that investigations impose upon suspects, victims, and their families. Time may affect the costs in each of these categories in different ways, increasing some and decreasing others.

This article will focus on the ways in which time can erode the ability of a criminal investigation to achieve the goals of criminal justice, and it will offer a tentative account of the circumstances in which a cold-case investigation is likely to be morally justified. Section 2 outlines the legitimate goals of a CJS. Section 3 examines the ways in which criminal investigation, as a particular component of this system, can serve these goals. This examination leads to an important distinction between contributions that investigations make directly to the achievement of criminal justice goals and contributions that they make by being instrumental to other criminal justice processes. Section 4 analyzes a number of ways in which the passage of time may affect the ability of an investigation to achieve these goals. Finally, we conclude with some general observations, following from this analysis, about the circumstances in which cold-case investigations are likely to be morally justified. 


\section{The goals of a criminal justice system}

A CJS is composed of a number of processes and institutions designed to identify certain actions as criminal offences and to respond to them in an appropriate manner. Construed broadly, this definition may encompass both the means by which criminality and the responses to it are legislated for and the means with which to deal with specific criminal actions. With respect to the latter, a CJS would normally be expected to respond to criminal wrongdoing by seeking to identify the agent or agents responsible; to hold them to account in accordance with a preestablished and fair procedure; to reach a judgment about their culpability; and to punish, rehabilitate, treat or release in accordance with the judgment. The launch of a criminal investigation is typically the first reaction that a CJS is able to initiate in response to a specific criminal act, and is the foundation on which many of the other responses depend. As we will see, however, criminal investigations can advance the moral goals of a CJS in a variety of ways.

In this section we itemize a number of such goals that are widely taken to be appropriate for a CJS to pursue. We do not offer an argument in favor of any particular account of the proper goals of a CJS. These are well-rehearsed in the literature, and an evaluation of the contending claims is beyond the scope of this article. We do not claim that any particular goal is morally mandatory for a legitimate and morally acceptable CJS. We do claim that a CJS, or a criminal investigation, that promoted none of these goals would be difficult to reconcile with commonly held notions of criminal justice. Our aim here is not to mount a defense of any particular vision of criminal justice, but to provide an overview of the variety of goals that criminal investigation, as a constituent part of the criminal justice system, might be expected to serve.

The aspect of a CJS that has received the most sustained philosophical attention is punishment. Although only one of the various operations that make up a CJS, punishment is a particularly crucial operation, being both the end to which many of the other operations are directed and the means by which the CJS seeks to accomplish some of its fundamental goals. The goals that punishment aims to achieve are conventionally divided into the retributive, the consequentialist, and the expressive or communicative, although in reality the division is not as neat as this classification suggests. 
From a retributivist perspective, the primary function of a CJS is to deliver punishment for criminal wrongdoing to those who deserve to receive it. There are a number of importantly different elaborations of why punishment of criminal activity is required (or at least permitted) by justice. ${ }^{3}$ Some accounts depict punishment as a specific manifestation of the general obligation to distribute harms and benefits in accordance with desert. Others emphasize the etymological core of retribution, the payment of a debt. ${ }^{4}$ Some focus upon the unfair advantage that criminal behavior can confer upon offenders and regard punishment as a requirement that issues from the interests of rule-abiders. These quick sketches indicate retributivism's distinctive motivating thrust. For the retributivist, punishment is justified as a response to the (criminal) acts and/or intentions of the offender, independently of its effects or utility. For this reason, retributivist justifications are often described as "backward-looking" in contrast with "forwardlooking" consequentialist justifications. Whether the goal of retribution is sufficient to justify imposition of punishment, or whether it can do so only in conjunction with other considerations, is a matter of long-standing controversy between retributivists, consequentialists and proponents of hybrid theories such as "limiting retributivism.",

The consequentialist goal most frequently cited as justification for the punitive function of a CJS is that of securing public safety via removal or "containment" of threats (often achieved through imprisonment), general and specific deterrence, and rehabilitation. In addition to reducing the incidence of crime, these measures may have a number of beneficial effects through their influence on people's perceptions. They may, for example, enhance psychological well-being by reducing the fear of crime or promoting a sense of belonging to a community that values justice and protects individuals, and these effects in turn may encourage valuable forms of activity and constructive engagement with the state and its institutions.

Although the goal of increasing public safety through punishment is usually articulated in relation to the public at large, the benefits may be especially significant for victims of crime, for whom a sense of security and of investment in society may need not only to be maintained but restored. These processes may also promote psychological "closure," enabling those affected by crime to exercise some control over the negative effects that the experience has upon their lives and helping to restore a personal sense of moral balance. In this respect the backward-looking goal of retribution may have a forward-looking counterpart in the victim's sense that justice has 
been done. There may also be opportunities for persons offended against, or their families, to confront the offender with their crimes as part of a process of "restorative justice," to have input into sentencing decisions, or to testify before parole boards contemplating an offender's release.

The third goal commonly associated with punishment is that of expressing or communicating social attitudes. ${ }^{6}$ The fact of punishment and the process leading to its imposition constitute powerful expressions of society's disapproval and condemnation of criminal actions. It is unclear whether the expressive function of a CJS should be regarded as independent of its deterrent or consequentialist goals. Expressing society's disapproval of criminal wrongdoing may be regarded as an important function regardless of any further benefits. However, it might also be considered to contribute to the retributive function of punishment as part of a process of shaming those who have earned opprobrium. It may also contribute to crime reduction, for example, through the deterrent effect of public disapproval, by consolidating useful social accords about criminality, or as an essential part of a process of reintegrating offenders into society.

In addition to these goals, a CJS may serve a number of others that are less closely tied to the notion of punishment. In some jurisdictions, the benefit to victims may extend beyond that arising from the retributive and public safety functions of punishment to include, for example, financial compensation (either from the state or from the offender through mechanisms of restorative justice) and access to a variety of support services (most obviously, counseling). In providing sufficient evidence to support the conviction of an offender, the CJS may benefit other actual or potential suspects, freeing them from 'institutional' suspicion and providing good grounds for the public to discard privately-held suspicions.

Finally, the CJS can provide explanations of (and more generally information about) crimes, typically involving an account of what happened, who did what, and why. These explanations may be relevant to the retributive goal of punishing in accordance with degree of culpability and may play a role in rehabilitation, reintegration of offenders and the prevention of reoffending. Beyond these functions, however, and independently of what happens to the offender, those who have been offended against may be entitled to, or benefit from, an explanation. More generally, explanations may serve at least two wider social purposes. First, they may help society to function despite the occurrence of crimes. Second, explanations may illuminate the causal factors 
that contribute towards crime in order to support crime reduction strategies. A full and accurate understanding of the reasons for which people do and don't commit crimes is of clear social utility. It is unlikely that the latter can be derived in any direct manner from the explanations of particular crimes provided within a CJS; nevertheless, the findings of criminal investigations may provide some of the data necessary to the relevant kinds of causal explanation.

\section{The contribution of criminal investigation to the goals of criminal justice}

The discussion so far has identified a number of moral goals that may serve as justifications for criminal justice activity. In this section, we will describe the specific role of criminal investigations in meeting these goals. We argue that while some of these goals are served by criminal investigations only where they lead to the activation of further steps in the criminal justice process, such as prosecution, conviction, and punishment, others may be served by criminal investigations independently of further steps. This distinction is important in the context of cold-case investigations because sometimes an investigation is the only viable part of the CJS process. If the investigation is not able to produce a prosecutable suspect, or sufficient evidence to lead to conviction, can it be justified on the strength of its contribution to the goals of the CJS?

Criminal investigations have three core purposes:

- to determine whether a crime has been committed;

- to determine the nature of the crime;

- to collect evidence that can cast light upon the identity of the person(s) responsible for the criminal act(s) and their degree of culpability. ${ }^{7}$

Police investigations are essentially fact-gathering exercises. Evidence is sought to supply a platform of facts upon which a theory about "what happened" might be constructed. Typically, when the police are satisfied that they have amassed sufficient evidence to support a plausible theory they present their findings to a body with authority to determine whether there is sufficient evidence to mount a prosecution. If it is determined that there is, criminal charges may be laid and the process of trying a person or persons for a crime begins. ${ }^{8}$ 
This sketch of the CJS reveals what might be called the subordinate nature of the investigative process. Rather than being free-standing, it is designed to facilitate holding individuals to account for criminal wrongdoing. In a legal system that serves the values of justice and fairness, individuals are entitled to proclaim their guilt or innocence and to answer the case made against them. Their case is judged according to a pre-established public process, and they are acquitted or convicted, sentenced and punished according to that judgment. Justice is taken to be served by the process as a whole when properly completed, and each stage is justified by the contribution it makes to the proper completion of the process as whole.

This characterization might suggest that criminal investigation should be embarked upon only where there is a reasonable expectation that the whole process will be completed. If criminal investigations are justified by their contribution to the successful completion of a (morally defensible) criminal justice process, it is hard to see why the costs they entail should be sustained where that end is unlikely to be achieved. Some margin of error might be tolerable - it might be acceptable, for instance, to conduct criminal investigations that appear at the outset to have the hallmarks of completability, even if the process is not in fact completed. But cases that have recognizably poor (or even hopeless) prospects at the outset may appear not to warrant investigation, given their unfavorable predicted cost-benefit ratio.

We want to present two kinds of argument that challenge this suggestion. The first is based on a practical point. Until an investigation has begun, it will generally be very difficult or even impossible to assess the likelihood of it leading to a successful prosecution. It may be useful to draw an analogy between criminal investigation and pharmaceutical research. When pharmaceutical scientists begin investigating a chemical compound, they cannot be sure that their efforts will be rewarded with a marketable product. A pharmaceutical product must clear many discrete phases of investigation, proving safety, tolerability, efficacy, and reliability. The new product must compete with currently available products and other treatments in development, and it must satisfy various intellectual property and cost-related requirements before it can reach the market. Consequently, every new compound investigated by scientists has, at the outset, only a small probability of producing a marketable medicine. ${ }^{9}$ Nevertheless, it is essential that such products are investigated in order for the valuable ones to be identified and medicine to progress. The same may hold true for criminal investigations: even leads with a low 
ex ante probability of leading to successful prosecution may be worth investigating, at least to some degree, in order not to miss those that will lead to successful prosecution. This is not to say that all leads should be investigated, irrespective of their prospect of leading to a successful prosecution. Even if we cannot be confident that any particular investigation will lead to a successful prosecution, there may be some that we can be fairly confident will not, and even if we cannot rule out altogether the possibility of a successful prosecution, it would be irrational, where resources are scarce and hard choices have to be made, not to take estimates of its likelihood into account in decisions about prioritization. Moreover, this argument from uncertainty will only support a limited investigation of unpromising cases: as the investigation starts to yield information about such things as the nature and age of the crime and the quality of available evidence, investigators will be in a position to make progressively better-informed judgments about the likelihood of successful prosecution.

The second argument is more directly normative. Even investigations that have very slim or nonexistent chances of producing a prosecution or conviction may in at least some cases serve some of the goals of a CJS. This means that, in some circumstances, a case can be made to embark upon an investigation that is very unlikely to facilitate further CJS activity, because the investigation itself advances important goals at a sufficiently small moral cost. Such investigations will, however, be harder to justify than those that are likely to lead to a successful prosecution, because a number of the key moral goals of a CJS are only served through the proper completion of the CJS process. In the remainder of this section we will examine this distinction and consider to which of the core goals of a CJS an investigation might contribute, independently of further steps in the criminal justice process.

A prime example of a goal that requires completion of the CJS process is retribution. Retributive justice requires that punishment be meted out in response to an offender's misdeeds, so it is essential that sufficient evidence is gathered to establish the nature of the deed, the identity of the offender, and the extent of criminal responsibility. Criminal investigation is thus necessary for the retributive goals of the CJS to be met. It is, however, the sentencing and penal processes of a CJS that lead directly to the achievement of retributive aims. The processes that precede this outcome, including criminal investigation, are of merely instrumental value as far as retributive aims go: if no one is charged, found guilty of, or sentenced for a given crime, then, however 
thoroughly the case has been investigated, the retributive function of criminal justice has not been advanced. An investigation that is highly unlikely to lead to a prosecution therefore cannot draw upon the goal of exacting retribution in its justification; if such an investigation is to be justified, it must be by reference to other goals.

Another example of a goal that requires completion of the CJS process is the securing of public safety via containment. An investigation that doesn't lead to prosecution and conviction does not advance the goal of isolating a dangerous person from society. Similarly, such an investigation cannot contribute to public safety via rehabilitation. This does not mean, however, that such investigations cannot contribute to public safety in other ways. Public safety may also be advanced via deterrence, both specific and general. Investigations may have both instrumental and independent deterrent value. Insofar as criminal investigations lead to prosecution and punishment, they may make an instrumental contribution to the goal of public safety accomplished via deterrence. However, criminal investigations may also have some deterrent value independently of conviction. This deterrence may take a specific or general form. The knowledge that their criminal activity has come to police attention and is under investigation may persuade some offenders to desist from crime, at least temporarily. ${ }^{10}$ Along with this specific effect, investigations have the potential to act as general deterrents. Police investigators' intrusions into private lives and their use of powers to seek information present some of the most visible and affecting displays of the potentially adverse consequences of crime upon criminals. The threat that is perceived to attach to these activities is likely to be strongly informed by beliefs about the ability of the CJS to deliver fully on that threat, so failures over time to detect and convict criminals could be expected to diminish the independent deterrent effect of criminal investigations. Despite this, it may not be necessary for any given investigation to produce a conviction in order for the people whom it touches to be deterred by it. So investigations with slim chances of securing convictions might be expected to retain some deterrent value, but suffer for their likely inability to contribute to public safety via removal of a threat or rehabilitation. What of other consequentialist goals?

Consider the welfare of victims of crimes. It can be anticipated that what this group most want from the CJS is for the offender to be identified, tried, found guilty, and punished. Insofar as criminal investigations facilitate this outcome, and insofar as victims' welfare is served by 
fulfillment of their wishes, criminal investigations make an instrumental contribution to this goal. But the contribution does not end there. A sensitively conducted and dedicated investigation can make a significant independent contribution to victim well-being. ${ }^{11}$ Whilst it is not the role of investigators to provide therapy, sensitively conducted investigations that show respect and concern for those adversely affected by crime may reasonably be expected to promote welfare. This may be especially important in those cases where the investigation does not lead to prosecution or punishment. In these cases an investigation that is conducted in a manner that reduces anxiety, provides assurance about the motivation and commitment of the CJS, and takes the needs of victims seriously, may make the failure to identify the offender or to successfully prosecute and convict easier to bear.

It is also important to consider the potential impact upon innocent suspects of investigations that are unlikely to lead to prosecution and conviction. When a CJS operates effectively, the adverse impact of criminal activity is made to fall, insofar as is possible, upon the offender, and efforts are made to reduce the adverse impact upon the lives of others, including innocent suspects. In providing sufficient evidence to support the conviction of an offender, a criminal investigation can allow for the exoneration of others who might be suspected, freeing them from institutional suspicion and providing good grounds for the public to discard privately-held suspicion. However, the effects of criminal investigation upon innocent suspects are far from being wholly beneficial.

The institutional and privately-held suspicions that an investigation may help to remove from an innocent suspect are in some cases drawn to the suspect by the investigation itself, and the removal, at least of the privately-held part of this suspicion may depend not only on the conclusions of the investigation, but on its leading to a successful prosecution of other suspects. The investigative process itself will often involve painful and difficult interactions between investigators and suspects, as investigators explore various possibilities and attempt to establish where criminal responsibility lies. Where suspects are innocent, these experiences are not personally warranted (that is, they are not the deserved product of their own actions), although they may be the inevitable by-product of an activity that is justifiable despite this negative impact. The suspicion cast upon innocent suspects and the invasive and painful means sometimes employed to determine whether suspicion is well-founded are moral costs of the investigative 
process, and these costs are only fully offset if a secure (and accurate) conviction is obtained. If the investigation does not culminate in a successful prosecution, its harmful effects may never be fully lifted from innocent suspects, nor justified by any benefits to society. The fact that criminal investigations do not advance or protect the welfare of innocent suspects independently of the CJS process as a whole is troubling, because it means that some people will suffer undeserved harms because of their involvement in a criminal investigation, harms that may never be relieved by the system itself.

At first sight, criminal investigations may do rather better at independently advancing the expressive goals of the CJS. The process of investigating criminal actions has important expressive or communicative functions that are both instrumental and independent. The instrumental component is obvious: investigations enable offenders to be prosecuted, sentenced, and punished for their illegal acts, sending out a powerful message about society's disapproval. Criminal investigations are also able, independently of any prosecution or conviction, to deliver powerful messages about the perceived gravity of offences and about society's commitment to holding offenders to account and protecting its citizens. For example, the number of officers assigned to an investigation, the use of technical equipment and expertise (heat-seeking technology, forensic evidence collection and analysis, police divers), and the systems that are established to deal with certain categories of crime can speak volumes about the commitment of the CJS to justice within a certain sphere. In contrast, a very different message is communicated through, for instance, careless or disrespectful collection of evidence from a woman who claims to have been raped, or thoughtless and inexpert taking of statements from a child witness. The persistently shoddy treatment of Stephen Lawrence's family by police during the investigation of his murder provides a telling example of the immense message-bearing power of investigations. ${ }^{12}$ However, while the expressive function of investigation does not depend wholly on achieving a conviction, the symbolism of a decision about whether to commit resources to the investigation may be related to the prospects for a successful prosecution. The Lawrence case seems to express a shocking lack of concern about the killing of a black teenager because of the sense that opportunities to obtain convictions were lost. Where the prospects for successful prosecution are small or non-existent (as in the case of Emma Alice Smith), a decision to scale down or abandon an investigation is less likely to be taken as expressing a lack of concern. Thus, 
the independent expressive value of investigations may be weaker than first appears in cases where completion of the criminal justice process is unlikely or impossible.

Criminal investigations also contribute both directly and indirectly to the provision of satisfactory explanations of crimes. In gathering evidence, investigations enable criminal trials to be held, providing a platform for the public provision, consideration, and assessment of competing explanations of a given crime. But the evidence that they collect can serve explanatory purposes even in the absence of a trial. In the case of murder-suicides, for example, a criminal investigation can ensure that multiple murder is not wrongly dismissed as murdersuicide, enabling the real offender to go free. Explanations of motives and means can also help relatives and the wider community to come to terms with a traumatic event, and help us to understand what leads people to such acts and how they might be prevented.

We have seen in this section that while some criminal justice goals, notably those relating to retribution, rehabilitation, and containment are served by investigation only through its role in securing conviction and punishment of offenders, other CJS goals - including securing public safety via deterrence, promoting the welfare of victims of crime, expressing disapproval of crime and respect and concern for its victims, and furthering our understanding of criminal acts - can to some extent be advanced by criminal investigations independently of the further processes that they are designed to facilitate. ${ }^{13}$ This distinction is important for the purposes of this paper because a characteristic of many old crimes, notwithstanding advances in forensic technologies, is that prospects for achieving a conviction are slim, or in some cases non-existent.

It is important to note, however, that this is not the only reason why the investigation of an old crime may be harder to justify than investigation of a more recent one, and that the relationship between the passage of time and the prospects for securing a conviction is not straightforward. In the next section we consider what we take to be the key ways in which the passage of time may bear upon the achievability of CJ goals.

\section{Assessing the justifiability of cold-case investigations}

In this section we reflect on a range of factors that relate the passage of time to the achievability of criminal justice goals. 


\section{Seriousness of the crime}

The seriousness of the crime is an obvious candidate for inclusion among the factors affecting the moral case for launching a criminal investigation, but is not as straightforwardly related to the passage of time as the other factors to be considered below. One way in which it may be time-related is in relation to changes in social attitudes to or judgments about the seriousness of certain types of crime. A crime that may not have been treated as especially grave at the time it was committed may now be taken much more seriously, while acts that were considered to be significant crimes when they were committed may now be considered less serious or even not to be crimes at all. Although we will not consider this question in any detail, it seems to us that the importance of investigating such crimes can only be assessed according to our current judgments. We can see no compelling case for investigating an action that is no longer considered to have been worthy of criminalization, and in the case of a crime considered more serious than when it was committed our previous underestimate does not seem a good reason to ignore the seriousness that we now attribute to it. ${ }^{14}$

The relevance of seriousness to decisions about cold-case investigations is not, however, limited to those cases in which prevailing assessments have changed. When considering contemporary crimes, the seriousness of the crime has an obvious bearing on the appropriateness of investigation. This is so partly for reasons to do with the allocation of scarce resources. Given that resources do not permit the investigation of all purported crimes, some method of assigning priorities must be found. Prioritizing more serious crimes (where seriousness is understood in terms of the amount of harm caused to the direct victim or society more generally) makes sense because the gains made with respect to the moral goals of the CJS will tend to be greater the more serious the crime. Even leaving aside questions of resource allocation (and, by implication, opportunity costs), a relatively trivial crime may not justify intrusions into the lives of innocent suspects. The same considerations apply to cold-case investigations. Given that resource constraints preclude the re-opening of every unsolved crime on the books, we must prioritize; and, irrespective of competition for resources, the seriousness of the crime will have a bearing on whether the gains in terms of CJS goals outweigh the costs of investigation.

Seriousness of the crime is of course not the only consideration affecting the moral viability of either new or cold-case investigations. In cold cases, time-related factors will tend to increase the 
costs of an investigation and diminish the extent to which it can achieve the range of CJS goals described above, so the threshold level of seriousness necessary to warrant investigation will tend to increase with time. A crime serious enough to be worthy of investigation in its immediate aftermath may not be so after the passage of several decades: a sudden increase in shoplifting in a particular locality may warrant investigation if it happens now, but a similar outbreak in the 1970 s is unlikely to be worth pursuing now, even if new leads come to light. ${ }^{15}$ The seriousness of the crime may therefore be considered to provide a baseline for assessing the value of a cold-case investigation, with the final judgment depending also on a range of time-related factors, such as will be considered in the remainder of this section.

\section{Time and evidence}

The presumption that prospects for obtaining good quality evidence diminish with the passage of time is an important factor in the justification of the statutes of limitations that exist in many jurisdictions. In many respects this presumption is justified. Physical evidence can deteriorate. Memories can be lost or become less reliable with the passage of time and as a result of ageing. Witnesses can be harder to identify and locate. Besides affecting the chances of reliably identifying the offender, these factors may make it harder to locate and detain them, and to assess the extent of their moral and legal culpability. These and similar considerations may lead some to conclude that beyond a certain timeframe, the prospects of obtaining a safe conviction are too slim to justify the costs of a police investigation. ${ }^{16}$

An investigation that does not produce enough evidence for a successful prosecution cannot perform what we have called its instrumental role in achieving the goals of criminal justice. We saw in the previous sections that a criminal investigation may serve some of the goals of the CJS even where it does not lead to a successful prosecution. This too, however, is likely to be compromised by a lack of reliable evidence. The deterrent effect of an investigation (both specific and general) is likely to be weaker if police are not seen to be getting close to the offender and appear to be going through the motions of an investigation without realistic expectation of success. The ability to provide explanations that will be either useful or therapeutic will be limited in the absence of reliable evidence. And while an investigation in these circumstances may have some symbolic value as an expression of society's attitudes, as 
argued above, this value is likely to be less significant where more concrete reasons to investigate are absent.

As we noted at the outset, however, developments in forensic technology challenge the assumption that the passage of time leads inevitably to a lack of reliable evidence. The reason that cold crimes have become a hot topic, and that many jurisdictions have abandoned or weakened statutes of limitations, is that genetic and other technologies are capable of providing robust evidence even after long periods of time and even in cases that were previously shelved due to a lack of evidence. In this manner the passage of time can in some cases increase rather than diminish the prospects for successful prosecution.

The prospects for this will clearly vary from case to case, so any decision to reopen a cold case needs to be based on an assessment of the evidence in the light of available technologies. Reopening a case that was previously closed due to lack of evidence will generally require either that new evidence has come to light or that new techniques allow the existing evidence to be analyzed in ways that were not possible before. ${ }^{17}$

\section{Time and death}

\section{The offender}

Another factor that may preclude successful completion of the criminal justice process is the ageing and eventual death of the offender. One reason why the cases of Ötzi and Jack the Ripper might seem so obviously inappropriate for police investigation is the certainty that the offender in each case is dead. As in lack-of-evidence cases, the death of the offender prevents a criminal investigation from furthering the goals of criminal justice by facilitating prosecution and punishment. One cannot extract retribution from a corpse. Containment, rehabilitation, and specific deterrence are neither possible nor necessary. These factors may perhaps explain the decision of Emma Alice Smith's sister not to tell the police of the deathbed confession that she (allegedly) received, and of the Sussex police not to launch a full-scale investigation. But what of the other goals that can be achieved by an investigation independently of its role in achieving prosecution and conviction? Can these justify launching an investigation where the length of elapsed time gives us reason to believe that the offender is dead, or where we have other, more direct reasons for believing this to be the case? 
One of the criminal justice goals that an investigation can serve independently of prosecution and conviction, and which may survive the death of the offender, is general deterrence. In discussing weakness of evidence as a problem for the investigation of old crimes we noted that the deterrent effect of an investigation may be weak if police are not seen to be getting close to the offender. The situation is somewhat more promising where the obstacle to prosecution is not lack of evidence but the death of the offender. Even though deceased offenders cannot be prosecuted, it may be possible to identify them and to assemble enough evidence of their guilt to lead others to believe that they will be at risk of prosecution if they commit similar offences.

Another goal able to survive the death of the offender is that of serving the welfare of those affected by a crime, including victims, their families, innocent suspects and their families. Although victims will not have the satisfaction of seeing the person who has wronged them punished, or of receiving an apology or reparations, it is possible that the achievement of a sense of closure may be assisted by the identification of the offender and explanation of his or her actions. If this is even a possible outcome then the fact that efforts are expended towards this end may serve to promote or restore the victims' sense that society takes seriously the wrong that they have suffered and is committed to protecting their welfare. Although these aims may not be as fully realized as they would be if a prosecution could be obtained, the death of the offender is less of an obstacle to their realization than a lack of evidence, since the former, unlike the latter, allows for a tangible outcome (an identification and perhaps an explanatory narrative) to be presented to the victims, which in turn makes the investigation less tokenistic and hence enhances its expressive function. Similar considerations will apply to the expressive and explanatory functions of criminal justice considered in relation to society as a whole rather than just to the interests of victims; society's disapproval of a criminal act and its commitment to a shared sense of justice may be less powerfully expressed in an investigation that is unable to produce a prosecution owing to the death of the offender, but efforts to identify the wrongdoer and explain what happened may nevertheless serve this function to a worthwhile extent in some cases.

Earlier in the discussion we indicated that exoneration of innocent suspects had a limited role to play in justifying investigations that will not lead to prosecution, since investigations may be responsible for causing as well as lifting suspicion, and since suspicion may not be fully lifted 
from innocent suspects until the real offender is convicted. However, in some cases these factors may be weaker than was earlier indicated. Where suspicion already exists (perhaps as a result of previous, failed investigations), the re-opening of a case may not add significantly to the burden already borne by innocent parties. And where the impossibility of convicting the offender is due not to an absence of evidence but to the offender's death, it may be possible for a police investigation to build a strong enough case against the offender, even if it is not tested in court, to effectively exonerate those who have been wrongly suspected. In cases where new genetic evidence is available, it may be possible to exonerate an innocent person whose reputation has been tarnished by suspicion even if it is not possible to identify alternative suspects. ${ }^{18}$

\section{The victim}

We have seen that the probable or certain death of the offender typically weakens the case for investigation of a crime by removing some grounds for it and weakening others, but that in some cases sufficient grounds may remain. What about the deaths of the victim of the crime and others harmed by it? A deceased victim of crime cannot experience any benefit from its investigation or from the punishment of the offender, yet the fact that murders are considered to be among the crimes most worthy of a response by the CJS suggests that the death of the victim does not necessarily undermine the case for investigation.

One reason for this may be that our obligations to people can survive their death. This thought is expressed in the common suggestion that we owe it to the victims of unlawful killings (not just murders but also negligent accidents) to bring those responsible for their deaths to justice. But if this is true of people recently killed, is it also true of those killed in the more distant past - Emma Alice Smith for example, or $\underline{\text { Ot}} t z i$ ? And what about people who have suffered non-fatal harms but have died subsequently from unconnected causes? If we owe the same obligations to members of all these groups then it seems that our obligations to current and recently deceased people will be overwhelmed by the sheer volume of our obligations to those of the more distant past. A more intuitively plausible position might be that we owe post-mortem obligations only (or at least more strongly) to the recently dead. Such a view might be supported by the thought that postmortem obligations are not general obligations that we have to everybody in virtue of their humanity, but special obligations arising from relationships that are more meaningfully asserted in the case of those who were, or were recently, our contemporaries. This would suggest that 
while the case for investigating an old crime does not disappear with the death of the victim, it will weaken progressively with the passage of time.

Another consideration also supports this view. In referring earlier to the interests of victims our examples involved experiential elements of welfare, such as feelings of closure, security and investment in society. If we do have obligations to the deceased, they cannot be obligations to promote or protect their experiential welfare but must be based on non-experiential values such as respect. It seems plausible to assume that if we owe such obligations to deceased victims, then we also owe them to living victims in addition to obligations to promote or protect experiential aspects of their welfare. It seems therefore, that in aggregate our obligations to the dead will be less extensive than our duties to the living.

It is beyond the scope of this article to defend either this particular view about obligations to the deceased, or indeed the view that such obligations exist at all. However, this is not the only reason for investigating crimes in which the victim is dead, and other less controversial reasons will lead to similar conclusions regarding the justifiability of cold-case investigations.

Almost all cases of recent crimes involve relatives and friends of the victim who may be regarded as indirect victims of the offence and who stand to benefit from the direct and indirect outcomes of an investigation in much the same way as a surviving victim (although usually to a lesser degree). So, much may be said for an investigation that is able to provide explanations and factual narratives, to express condemnation of the crime and solidarity with its victims, and perhaps to facilitate prosecution of the offender, even leaving aside any post-mortem obligations to the direct victim. In older cases, such as that of Emma Alice Smith, however, it is likely that many or all of the people who knew the victim will themselves have died. In still older cases we may be certain that neither the victim nor anyone who knew them remains alive. In such cases there will be less reason to pursue an investigation.

Even where the victims and all those who knew them are dead, there may be reasons to pursue an investigation. Often the offender will also be dead in such cases, but this is not necessarily the case. If the offender is still alive and capable of being prosecuted, then considerations of retribution, rehabilitation, containment, and specific deterrence may still apply. Even if both victim and offender are dead, some of the impersonal goals of the CJS may remain relevant, 
including general deterrence, expression of society's condemnation of certain kinds of act, and the provision of explanations. As we will see, however, these are likely to have limited force.

\section{Innocent suspects}

Removal of false suspicion was identified earlier as one of the goals of investigation that can survive the death of the offender, provided that sufficient evidence exists. Like the direct victims of a crime, innocent suspects have suffered a harm that a criminal investigation may be able to redress.

As with the deaths of the direct victims considered in the previous subsection, the death of the falsely suspected leaves open the (albeit controversial) possibility that we owe them post-mortem obligations (to clear their reputations), which may be served by a criminal investigation. If there are such duties and, as suggested above, they are special duties arising from our relationship to the deceased, they may be stronger where the false suspicion has been created or perpetuated by the previous actions of the CJS. However, even if such duties exist, they are likely, as in the case of direct victims, to be less strong than duties to protect and restore the reputation of innocent suspects who are still alive to suffer the experiential effects of wrongful suspicion.

Continuing the parallel with direct victims, the reputational damage caused to innocent suspects may live on after their deaths in the experiences of their friends and family, although eventually these too will be gone. While in principle such harms could be transmitted down the generations, it becomes increasingly implausible as the distance from the suspect increases, to think that the persisting harms would be of a degree that would justify investigation in the face of competing demands for resources.

\section{Time and the living}

\section{The offender}

We have considered the effect on the justifiability of a cold-case investigation of the deaths of those most directly involved in it: the offender, the victim, and innocent suspects, as well as those who are affected in virtue of their relationship to one or another of these. But not all coldcase investigations will involve criminals, victims, or suspects who are now deceased. Child sexual-abuse cases, for example, are often reported when the victim is in adulthood and the 
offender is in old age. In these situations, the cases are cold, but the relevant persons are contemporaries. Cases in this category may be viewed as having a greater claim upon police resources than similar cases in which the relevant persons have died, but some hesitation may remain. Can the passage of time reduce the value of a criminal investigation even when those involved in and affected by the crime remain alive? In this section we consider reasons relating to the status and interests of the persons involved; in the next section we will consider reasons relating to wider social interests.

One reason why the case for an investigation may diminish over time, even while those involved in it remain alive, relates to theories about personal identity and responsibility. A theory of personal identity gives an account of the conditions under which a person existing at one time is the same person as one existing at another time. This consideration is important for criminal justice, since a person can only justifiably be punished for a crime that he or she committed. If the person who is punished is not the criminal, then a miscarriage of justice has occurred; in this case retributive goals are not achieved, and an injustice is committed against the person who is punished.

According to psychological theories of personal identity, the identity of a person existing at $\mathrm{T}_{2}$ with an earlier person existing at $\mathrm{T}_{1}$ is not guaranteed by the fact that they inhabit the same body, but depends on the degree to which they are psychologically connected in terms of such things as memories, intentions, beliefs and dispositions. In order to be intuitively plausible, such theories must allow that identity can endure some loss of memory and changes in beliefs and attitudes to occur over time. In recognition of the transitivity of identity (if A is identical with B and B is identical with $\mathrm{C}$ then $\mathrm{A}$ is identical with $\mathrm{C}$ ), most accounts hold that personal identity can be maintained by overlapping chains of psychological links, even if no direct connections obtain between $\mathrm{T}_{1}$ and $\mathrm{T}_{2}$. Thus I am the same person as the young child who developed into me if the child has sufficient connections to the teenager and the teenager to me, despite an absence of direct links between me and the child.

It follows from this account that even given the tendency of memories to degrade and other psychological attributes to change over time, personal identity will not be inevitably lost over time, and it is likely that loss of identity will only be an obstacle to the achievement of CJS goals 
in circumstances where a severe breakdown of mental functioning has occurred; for example, where the suspect suffers severe dementia. The CJS goals that can and cannot be achieved in such cases will be similar to cases in which the offender is dead, except that the continued physical existence of the offender may make goals involving identification of the offender and explanation of the crime somewhat more achievable.

Psychological connectedness between a person at the time he or she committed a crime and at the time of investigation may be relevant in another way. Derek Parfit articulates an intuitive view about the way in which the degree of connectedness may affect the extent to which persons are deserving of punishment for their past crimes:

When some convict is less closely connected to himself at the time of the crime, he deserves less punishment. If the connections are very weak, he may deserve none. . . . Just as someone's deserts correspond to the degree of his complicity with some criminal, so his deserts now, for some past crime, correspond to the degree of psychological connectedness between himself now and himself when committing that crime. ${ }^{19}$

This contentious view ${ }^{20}$ warrants a fuller analysis than we have space to develop here. It does suggest, however, that psychological changes that happen over time, even if they are not sufficient to undermine personal identity, might undermine the case for retributive punishment. For instance, religious conversions or experiences of moral enlightenment (or degeneration) that bring sufficient psychological change to remove a person's sense of personal identification with his or her previous self might lead us to question the appropriateness of retributive punishment. Such changes, if they make repeat offending unlikely, might also undermine the case for containment, rehabilitation, and specific deterrence. ${ }^{21}$ These latter goals may also be undermined by physiological or psychological changes that do not involve moral character but diminish the offender's capacity to commit further crimes.

However, although this argument may apply in cases where the personal identity argument does not, it shares with it the limitation of only being applicable on a case-by-case basis. An offender will not inevitably undergo psychological changes of a kind that would undermine the case for punishment with the passage of time. It is unlikely, therefore, that this phenomenon will yield 
grounds for de-prioritizing investigations, except in cases in which a particular suspect has already been identified.

\section{The victim}

Similarly to what we have seen with the offender, psychological changes undergone by the victim may affect the ability of a delayed investigation to achieve the goals of a CJS. As in the case of the offender, we can distinguish between cases in which the loss of psychological continuity is so severe as to undermine the victim's personal identity, and cases in which personal identity is maintained but the psychological connection between the victims as they are now and as they were at the time of the crime is weakened. The former, as in the case of the offender, is likely to be comparatively rare, but where it does occur will have an effect on the justifiability of investigation similar to the biological death of the victim.

\section{Time and society}

We have examined ways in which those goals of criminal investigations that involve doing things to or for the people directly connected to a crime - offenders, victims, and innocent suspects - can be affected by the changes that time brings to these individuals. But what about the goals that relate to the interests of society at large? How might they be affected by the passage of time?

\section{General deterrence}

One such goal is the promotion of public safety. We have observed that containment, rehabilitation, and specific deterrence cease to be effective means to this end where the offender no longer poses a threat to public safety. General deterrence may be weakened where the demonstrative potential of prosecution, conviction, and sentencing is taken away by the death of the offender, but may retain significant justificatory force where it is possible to assemble and present evidence that could have led to a conviction had the offender still been alive. For example, the very public investigations into the sexual offences alleged to have been committed over many years by the British entertainer Jimmy Savile, although not undertaken as police investigations and not instigated until after Savile's death, may dissuade potential offenders in similar positions of influence from believing that such offences can remain hidden. 
Viewed from one perspective, the deterrent effect of cold-case investigations could be substantial, suggesting that there is never a temporal place of safety for the (serious) criminal. ${ }^{22}$ On the other hand, we know that people tend to heavily discount future harms (and benefits), perhaps in part because of a weaker sense of connectedness with their more distant future selves. To work most efficiently, deterrence appears to require a strong belief in the likelihood of conviction. This belief may be enhanced by cold-case investigations that demonstrate the ability to assemble evidence capable of supporting a prosecution many years after the event. However, the tendency to discount, and in some cases the lack of opportunity for prosecution or the difficulty of building a convincing case, may mean that the deterrent effect of a much-delayed criminal investigation is less than that of a more timely one, and therefore that the evidence will need to be stronger, or the offence more serious, in order to justify the investigation on grounds of deterrence.

\section{Expression and explanation}

We noted above that the expressive and explanatory functions of investigation may survive the death of the offender. Even these functions, however, may be weakened by the passage of time. One limitation is that they have a victim-focused aspect that will be lost or weakened where the victim has died or achieved a degree of closure in other ways. It may, nevertheless, be important to society, aside from any benefit to the victims, to explain serious crimes, or to take action that expresses society's disapproval. Considering again the posthumous investigations into the abuses committed by Jimmy Savile, it seems reasonable to suppose that, aside from any direct benefit to his victims, these investigations will play a part in the clarification and promulgation of shared values relating not only to Savile's actions and others like them, but to the contextual factors that allowed them to happen. Explanations of how Savile was able to get away with his activities for so long may help institutions and society at large to design safeguards against such abuses happening in the future. The expressive value of an investigation, as we have noted, may be diminished where no other end (such as retribution or public safety) is served, and explanations may be of less value where the crime in question is far removed from current realities.

These functions may be most able to retain their relevance over long periods in the context of crimes that have affected large numbers of people, or that have been perpetrated or allowed by collective bodies such as governments, political parties, companies, and religious or charitable 
organizations. Allegations relating to war crimes, child abuse, or collaboration with tyrannical and illegitimate regimes can fall into this category. The goal of investigations of this scale might not be to bring a prosecution, as the guilty parties may be dead or too ill to stand trial. Rather, investigation acts as a symbol of the responsibility of the organization and as an acknowledgement of the legitimate and serious complaint that victims, their families, and society in general have against the organization as well as specific culpable individuals.

\section{Conclusion}

We have examined a number of time-related factors that may, either gradually or more abruptly, affect the ability of a criminal investigation to serve CJS goals. Different goals are affected by different factors and to different degrees, but some are relatively resilient to the passage of time, and so may provide prima facie justification for opening or reopening an investigation even after many years have passed, and after the deaths of some or all of those involved in or directly affected by a crime. Factors affecting the achievability of CJS goals, such as the death or changed psychological state of those involved, although predictable in some circumstances, do not relate uniformly to the passage of time. The degradation of evidence may even be reversed by the development of new technologies. This assessment suggests that assessment of the moral viability of potential cold-case investigations ought to be undertaken on a case-by-case basis.

Some general conclusions may nevertheless be drawn. A cold case should normally only be reopened when new evidence has emerged, or when new techniques enable more information to be extracted from the evidence than was possible when the case was previously investigated. Exceptions arise where the previous investigation was improperly conducted or wrongly abandoned. In the case of previously investigated crimes and those that have only recently come to the attention of the authorities, there should be reasonable grounds for believing that the investigation can succeed - if not in producing a prosecution then at least in yielding information that is likely to be of benefit to victims, innocent suspects, or society.

Changes in the character, attitudes, interests, and even the identity of those involved in a crime, as well as those who know and care about them, may weaken the extent to which those goals of a CJS that relate to their interests and deserts can be achieved. However, while these changes 
become more likely with the passage of time, the relationship is not a linear one. It cannot safely be assumed, for example, that after a given time the offender will no longer be a threat to public safety or that victims will have forgiven the offender or restored the balance of their lives in other ways. In the absence of specific information, these considerations will have only a modest effect on the justifiability of an investigation - enough, perhaps, to lower its priority when resources are scarce, but not to rule it out of consideration.

Where it is known, or can reasonably be inferred from the passage of time, that the offender is dead, several important criminal justice goals will be unachievable and the achievability or impact of others is likely to be weakened. Although this makes it harder to justify assigning it a high priority, such an investigation may still be viable if it is likely to be of significant value to people currently alive, including victims, innocent suspects and wider society. The death of the victims and others directly affected by the crime likewise reduces the range of criminal justice goals that can be achieved, but leaves others potentially intact. Where the offender and the victims and others directly affected by the crime are (or are likely to be) dead, the case for investigation will be much weaker. Given competition for scarce police resources, it is likely that only the most serious crimes in this category - those which have the deepest impact on society at large, not just on individual victims - will be reasonable candidates for investigation.

Once we reach beyond the lifetimes of those involved with the crime and those closely connected to them, only the impersonal goals of expressing social attitudes and providing explanations remain theoretically viable. Even these, however, lose their force over longer periods of time, as the absence of more concrete goals make investigation look less like expression and more like futile tokenism, and as the relevance of any possible explanation to our own society fades, vindicating the intuition that while researching Jack the Ripper or Ötzi might be interesting and worthwhile activities for historians and archeologists, they are not appropriate uses of criminal justice resources.

\section{Notes}


1. The University of Michigan School of Law and the Centre on Wrongful Convictions at the Northwestern University School of Law maintains the National Register of Exonerations, which contains details about every exoneration in the United States since 1989. See https://www.law.umich.edu/special/exoneration/Pages/about.aspx.

2. Imwinkelried, "Relative Priority," 94.

3. John Cottingham describes and offers critical commentary upon nine justifications of punishment that are commonly (and, he argues, in several cases mistakenly) labeled retributive. See Cottingham, "Varieties of Retribution." See also Rachels, "Punishment and Desert"; and Walker, Why Punish?

4. Bedau, "Retribution," 604; Wolgast, "Intolerable Wrong and Punishment"; Cottingham, "Varieties of Retribution."

5. See Davis, "Recent Work"; Frase, "Punishment Purposes"; Hirsch, "Hybrid Principles"; Morris, "Future of Imprisonment"; Robinson, "Hybrid Principles."

6. See, for instance, Feinberg, "Expressive Function of Punishment"; and Duff, Punishment, Communication, and Community.

7. Criminal Investigators may be required to perform other, related tasks. In the case of some homicide investigations, one of the first tasks is to identify the victim. Investigators are generally expected to liaise with the victim's family and to inform them of their relative's death. This role is partially unrelated to the strict business of investigation of the crime, but only partially so: these interactions provide investigators with a crucial opportunity to access information or to get an impression of the dynamics of the family and to begin to rule people in or out of the investigation. See Doughty, "Sid, My Saviour” in The Guardian, September 18, 2010; and Innes, Investigating Murder. Other tasks include locating a body, keeping the public appropriately informed, and collecting data for administrative and analytical purposes.

8. Of course, strength of evidence may not be the only factor that determines whether a prosecution should take place. In some jurisdictions, for example, there is also a requirement that prosecution should be in the public interest. 
9. "The data indicate that the average success rate for all therapeutic areas is approximately $11 \%$; or, put another way, in aggregate only one in nine compounds makes it through development and gets approved by the European and/or the US regulatory authorities." Kola and Landis, "Pharmaceutical Industry Attrition Rates," 711.

10. Some empirical work suggests that heightened police presence and attention to certain sorts of criminal activity can have significant deterrent effects that in some cases outlast the “crackdown" period. In other cases, an initially potent deterrent effect appears to weaken over time. See Sherman, "Police Crackdowns."

11. "The process of being heard and taken seriously [by investigators] was more important to victims than the outcome of the case (i.e., whether the case went to trial)." Powell and Cauchi, "Victims' Perceptions," 233. See also Coupe and Griffiths, "Influence of Police Actions"; Russell and Light, "Police and Victim Perspectives."

12. Stephen Lawrence was an 18-year-old black man who was the victim of a racially motivated murder in London in 1993. A public inquiry was ordered by the British Home Secretary in 1997 to investigate alleged failings in the Metropolitan Police Service's handling of the case. It concluded that the investigation "was marred by a combination of professional incompetence, institutional racism and a failure of leadership by senior officers" (Macpherson, Stephen Lawrence Inquiry, 46.2). The report criticized, amongst other things, a "lack of direction and organisation during the vital first hours after the murder" (ibid., 46.6), delays in arresting suspects and searching premises (ibid., 46.6), inadequacy of the searches when they did take place (ibid., 46.18), and unsatisfactory handling of witnesses (ibid., 46.19). On the specific issue of the "insensitive and unsympathetic" treatment of Stephen's parents, the report states: "One of the saddest and most deplorable aspects of the case concerns the failure of the family liaison. $\mathrm{Mr}$ \& Mrs Lawrence were not dealt with or treated as they should have been. They were patronised. They were never given information about the investigation to which they were entitled" (ibid., 46.8).

13. The goal of promoting the welfare of innocent suspects straddles this distinction. The lifting of unwarranted suspicion can in principle be achieved by investigations that do not lead to 
prosecution (for example where they unearth strong evidence about the identity of the real offender, who is, however, dead or otherwise unreachable) but for many innocent suspects such considerations will be outweighed by the intrusion and creation of suspicion that results from investigation.

14. This does not mean, however, that the severity of punishment should track our current assessment of the crime's seriousness. This is a complex matter but one that needs to be addressed with sensitivity to the dangers that retrospective sanctions pose for the rule of law and the difficulty of holding people responsible for moral oversights that were commonplace in the society in which they lived.

15. The point may similarly be illustrated with more serious cases. Ötzi's death potentially bespeaks a serious crime; the horrendous murders attributed to Jack the Ripper are of the utmost moral seriousness, but they are not viable candidates for a police investigation so long after the event.

16. As noted above, we include in these costs not only the financial and opportunity costs of devoting police resources to an investigation that is unlikely to result in a conviction, but also the personal costs to suspects who are investigated but not subsequently convicted.

17. The exception would be a determination that the previous decision to close the case was mistaken.

18. The case of Muriel Drinkwater, reported in the Mail Online, November 7, 2008, provides an example of this possibility.

19. Parfit, Reasons and Persons, 326.

20. For an opposing view, see Lubcke, "What Matters?” especially 106.

21. A case in which these responses seem appropriate is that of Hélène Castel, reported in The Guardian, January 5, 2006.

22. For example, following the conviction of the broadcaster Stuart Hall for sex offences against girls committed between 27 and 45 years previously, a spokesman for Lancashire Police said: "The fact that these convictions have come a long time after they were committed shows that we 
will always take any allegations of sexual abuse extremely seriously and will investigate them thoroughly no matter how long ago they happened. We will always strive to protect our communities, no matter the status of the alleged perpetrator." Guardian, May 2, 2013.

\section{Bibliography}

Bedau, Hugo A. "Retribution and the Theory of Punishment." The Journal of Philosophy 75, no. 11 (1978): 601-620. http://www.jstor.org/stable/2025477.

Cottingham, John. "Varieties of Retribution.” The Philosophical Quarterly 29, no. 116 (1979): 238-246. http://www.jstor.org/stable/2218820.

Coupe, Tim, and Max Griffiths. "The Influence of Police Actions on Victim Satisfaction in Burglary Investigations.” International Journal of the Sociology of Law 27, no. 4 (1999): 413431. doi:10.1006/ijs1.1999.0097.

Davis, Michael. "Recent Work in Punishment Theory.” Public Affairs Quarterly (1990): 217232. http://www.jstor.org/stable/40435749.

Duff, Antony. Punishment, Communication, and Community. Oxford: Oxford University Press, 2001.

Feinberg, Joel. “The Expressive Function of Punishment.” The Monist 49, no. 3 (1965): 397423. http://www.jstor.org/stable/27901603.

Frase, Richard S. "Punishment Purposes.” Stanford Law Review 58, no. 1 (2005): 67-83. http://www.jstor.org/stable/40040252.

Hirsch, Andrew Von. "Hybrid Principles in Allocating Sanctions: A Response to Professor Robinson.” North Western University Law Review 82, no. 1 (1987): 64-72.

Imwinkelried, Edward J. "The Relative Priority that Should be Assigned to Trial Stage DNA Issues." In DNA and the Criminal Justice System, edited by David Lazer, 91-108. Cambridge, MA: MIT Press, 2004. 
Innes, Martin. Investigating Murder: Detective Work and the Police Response to Criminal Homicide. Oxford: Oxford University Press, 2005.

Kola, Ismail, and John Landis. "Can the Pharmaceutical Industry Reduce Attrition Rates?" Nature Reviews Drug Discovery 3, no. 8 (2004): 711-716. doi:10.1038/nrd1470.

Lubcke, Poul. "What Matters? On Parfit's Ideas of Personal Identity and Morality." Danish Yearbook of Philosophy 28 (1993): 99-114.

Macpherson, William. The Stephen Lawrence Inquiry: Report of an Inquiry by Sir William Macpherson of Cluny. Cm. 4262-1. London: Home Office, 1999.

Morris, Norval. The Future of Imprisonment. Chicago: University of Chicago Press, 1974.

Parfit, Derek. Reasons and Persons. Oxford: Oxford University Press, 1984.

Powell, Martine B., and Rita Cauchi. "Victims' Perceptions of a New Model of Sexual Assault Investigation Adopted by Victoria Police." Police Practice and Research 14, no. 3 (2013): 228241. doi:10.1080/15614263.2011.641376.

Rachels, James. "Punishment and Desert." In Ethics in Practice, edited by Hugh LaFollette, 510-518. Malden, MA: Blackwell Publishing, 2007.

Robinson, Paul H. "Hybrid Principles for the Distribution of Criminal Sanctions." North Western University Law Review 82, no. 1 (1987): 19-42.

Russell, Mary, and Linda Light. "Police and Victim Perspectives on Empowerment of Domestic Violence Victims.” Police Quarterly 9, no. 4 (2006): 375-396. doi:10.1177/1098611104264495.

Sherman, Lawrence W. "Police Crackdowns: Initial and Residual Deterrence.” Crime and Justice 12 (1990): 1-48. http://www.jstor.org/stable/1147437.

Walker, Nigel. Why Punish? Theories of Punishment Reassessed. Oxford: Oxford University Press, 1991. 
Wolgast, Elizabeth H. "Intolerable Wrong and Punishment.” Philosophy 60, no. 232 (1985): 161-174. doi:10.1017/S0031819100051068. 